\title{
Translational independence between overlapping genes for a restriction endonuclease and its transcriptional regulator
}

\author{
Meenakshi K Kaw ${ }^{1}$, Robert M Blumenthal ${ }^{1,2^{*}}$
}

\begin{abstract}
Background: Most type II restriction-modification (RM) systems have two independent enzymes that act on the same DNA sequence: a modification methyltransferase that protects target sites, and a restriction endonuclease that cleaves unmethylated target sites. When RM genes enter a new cell, methylation must occur before restriction activity appears, or the host's chromosome is digested. Transcriptional mechanisms that delay endonuclease expression have been identified in some RM systems. A substantial subset of those systems is controlled by a family of small transcription activators called C proteins. In the Pvull system, C.Pvull activates transcription of its own gene, along with that of the downstream endonuclease gene. This regulation results in very low R.Pvull mRNA levels early after gene entry, followed by rapid increase due to positive feedback. However, given the lethal consequences of premature REase accumulation, transcriptional control alone might be insufficient. In C-controlled RM systems, there is a $\pm 20 \mathrm{nt}$ overlap between the $\mathrm{C}$ termination codon and the $\mathrm{R}$ (endonuclease) initiation codon, suggesting possible translational coupling, and in many cases predicted RNA hairpins could occlude the ribosome binding site for the endonuclease gene.

Results: Expression levels of lacZ translational fusions to pvullR or pvullC were determined, with the native pvull promoter having been replaced by one not controlled by C.Pvull. In-frame pvullC insertions did not substantially decrease either pvullC-lacZ or pvullR-lacZ expression (with or without C.Pvull provided in trans). In contrast, a frameshift mutation in pvull $C$ decreased expression markedly in both fusions, but mRNA measurements indicated that this decrease could be explained by transcriptional polarity. Expression of pvullR-lacZ was unaffected when the pvullC stop codon was moved $21 \mathrm{nt}$ downstream from its WT location, or 25 or 40 bp upstream of the pvullR initiation codon. Disrupting the putative hairpins had no significant effects.

Conclusions: The initiation of translation of pvullR appears to be independent of that for pvullC. Direct tests failed to detect regulatory rules for either gene overlap or the putative hairpins. Thus, at least during balanced growth, transcriptional control appears to be sufficiently robust for proper regulation of this RM system.
\end{abstract}

\section{Background}

Bacterial type II restriction-modification (RM) systems are abundant in both the bacterial and the archaeal worlds [1]. Many play important roles in defense against phage [2], but they also appear to modulate horizontal gene transfer [3], and to act as "selfish" toxin-antitoxin addiction modules $[4,5]$. Type II RM systems generally specify separate DNA methyltransferase (MTase) and

\footnotetext{
* Correspondence: Robert.Blumenthal@utoledo.edu

'Department of Medical Microbiology and Immunology, University of Toledo Health Science Campus, 3100 Transverse Drive, Toledo, OH 43614-2598, USA Full list of author information is available at the end of the article
}

restriction endonuclease (REase) proteins [6]. Many type II RM systems are on mobile genetic elements, but even chromosomal RM systems can move into new host cells via transduction, transformation or conjugation [7-10].

PvulI is a plasmid-borne type II RM system from the Gram-negative bacterium Proteus vulgaris [11]. The MTase (M.PvuII) modifies the cognate DNA sequence CAGCTG by methylating the internal cytosine [12], generating N4-methylcytosine [13]; while the REase (R.PvuII) cleaves the central $\mathrm{GpC}$ if this sequence is unmethylated [13-15]. The REase and MTase act independently of each other in type II RM systems. As a

\section{Biomed Central}


result, strict regulation is needed after the genes enter a new cell in order to delay REase accumulation until the MTase has had time to protect the new host's DNA. The basis for this regulation is unknown for most RM systems.

A subset of type II RM systems are controlled by a third gene, that was designated as " $\mathrm{C}$ " (controller) protein when first discovered in the BamHI and PvulI systems $[16,17]$. Sequence comparisons quickly identified orthologs in the SmaI and EcoRV systems [17], and since then $\mathrm{C}$ proteins have been identified (and in some cases confirmed) in a wide variety of other RM systems [18].

The transcriptional regulation of C-controlled RM systems is understood in outline, from the structure of the C proteins [19-22], through their action at conserved " $\mathrm{C}$ boxes" upstream of the $C$ genes [7,9,23-27], to their dual function as activators and repressors [24] and possible interaction with RpoD $\left(\sigma^{70}\right)[7,20]$. The temporal behavior of one of these systems has also been studied, following its introduction into new host cells [28].

The PvuII genes naturally reside on a mobilizable plasmid $[8,12,29]$. When these genes enter a new host cell with no pre-existing C.PvuII protein, the MTase gene $(p v u I I M)$ is rapidly transcribed from a pair of C-independent promoters [7,28] (Figure 1A). The REase gene $(p v u I I R)$ has no separate promoter, and depends on two promoters upstream of the $\mathrm{C}$ gene pvuIIC [7]. One of these two promoters is weak but independent of C.PvuII. The resulting transcript begins $26 \mathrm{nt}$ upstream of the pvuIIC initiation codon [7] (Figure 1A), so translation relies on a ribosome binding site (RBS, also called a Shine-Dalgarno sequence) [30,31]. Because most of our experiments are carried out in $E$. coli, it is important that the 3' 60 nt of $16 \mathrm{~S}$ rRNA, which includes the "antiShine-Dalgarno" sequence complementary to the RBS, is identical in E. coli and P. vulgaris (e.g., compare GenBank accession numbers S000629954 with X07652 or J01874).

The RBS for pvuIIC is very poor (Figure 1B), based on the very limited similarity to an AGGAGG motif [32]. The expected poor translation initiation would synergize with the lack of transcriptional autogenous activation by C.PvuII [17], by slowing the elongation of any transcripts that did get produced [33]. In contrast, when C.PvuII eventually begins to accumulate, it activates transcription from the second promoter, rapidly boosting transcription of $p v u I I C$ and $p v u I I R$ via a positive feedback loop [7,28]. Furthermore, the resulting C.PvuII-dependent transcript is leaderless [7], beginning at the pvuIIC initiator codon, and is thus independent of the RBS [34-36].

A key area of uncertainty in this model is whether transcription-level regulation is sufficient to protect the cell. Early transcription from the weak $\mathrm{C}$-independent promoter appears to proceed into pvuIIR [28]. If pvuIIR mRNA can be translated well, independent of the rate at which the upstream $p v u I I C$ gene is translated, this might lead to unacceptably rapid early accumulation of restriction activity. Unlike pvuIIC, pvuIIR has an obvious RBS motif (Figure 1B). We accordingly investigated whether there is some form of translational control of pvUIIR.

We were particularly intrigued by two features of the PvuII genes: first, the pvuIIC and pvuIIR genes overlap, and second, $p v u I I R$ is preceded by potential hairpins,

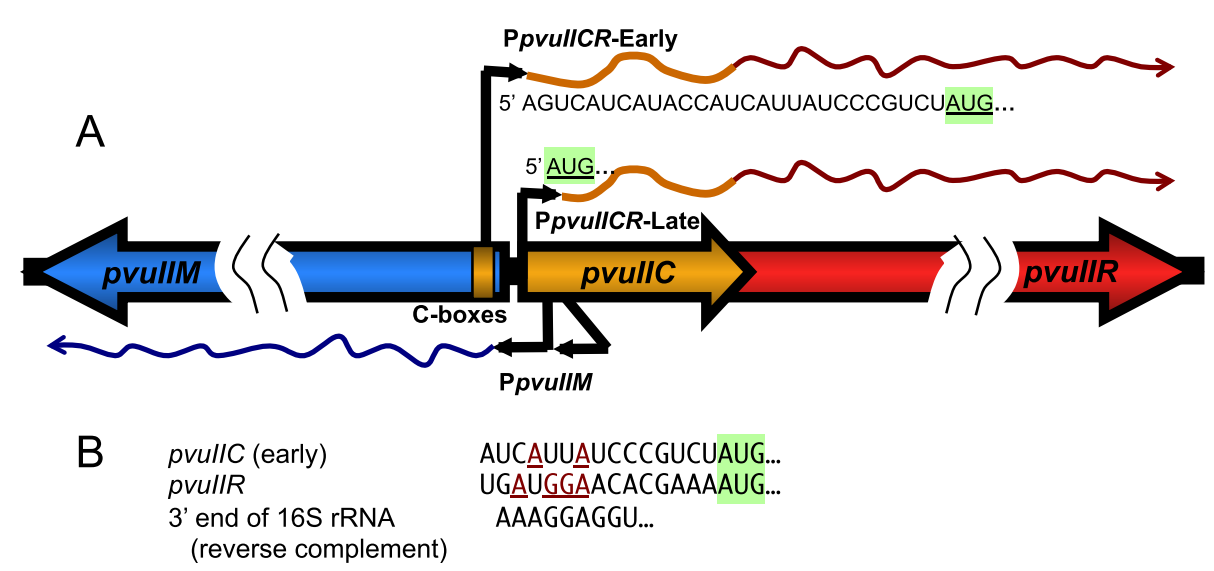

Figure 1 Pvull transcripts. A. The diagram indicates the expected transcripts early or later after the Pvull genes enter a new host cell. The timing is inferred from in vivo transcript mapping in the presence or absence of active C.Pvull [7], and following synchronous infection of cells with bacteriophage carrying the Pvull genes [28]. "C boxes" are the binding sites for the autogenously-activating $\mathrm{C}$ protein. The two pvullM (methyltransferase) promoters appear to be constitutive. B. The ribosome-binding (Shine-Dalgarno) sequences are predicted based on location relative to the pvullC start codon (shaded green), and comparison to the Logo for ribosome binding sites adapted from [32]. 
one of which would occlude the pvuIIR RBS. The pvuIIC and pvuIIR genes are cotranscribed [9], and many polycistronic transcripts require translation of an upstream gene for efficient translation of a subsequent gene. This phenomenon, resulting from poor loading of free ribosomes onto the internal translation initiator, is called translational coupling, and was first observed in the tryptophan operon of E. coli [37]. Coupling might play an important role in delaying REase accumulation in C-controlled RM systems, relative to that of MTase, after the genes for the system enter a new host cell. The frequent proximity between the $\mathrm{C}$-gene terminators and $\mathrm{R}$-gene initiators in C-protein-controlled RM systems (Figure 2) is suggestive of translational coupling [38,39]. Regarding the hairpins, they were noted in earlier studies, and at least one of them could explain termination products seen in some primer extension experiments [9]. In addition to the overlap and hairpins, in another C-controlled RM system (Eco72I), the C protein itself has an apparent translational regulatory role [25]. Accordingly, we also tested the ability of C.PvuII to affect translation of pvuIICR mRNA in trans.

\section{Results}

\section{Translational lacZ fusions to pvullC and pvullR}

To explore possible translational coupling, we made lacZ translational fusions to the pvuIIC and $p v u I I R$ genes (Figure 3A; Methods). Importantly, in these fusions, transcription is from PlacUV5 and is independent of C.PvuII. Furthermore, the vector's RBS is used, ensuring consistent and efficient translation initiation of pvuIIC.

We first measured $\beta$-galactosidase activity from WT fusions (see lines 1 and 3 of Figure $3 \mathrm{~B}$ for junction sequences). Over the course of exponential-phase growth, the plot of activity vs. culture density should be linear if the culture is in balanced growth and the assay is in the linear range. The resulting slopes give a precise measure of relative activity. Using this approach, the level of expression of the WT pvuIIR-lacZ translational fusion was not significantly different from that of the WT pvuIIC-lacZ fusion (Figure 4). Providing WT C.PvuII (or a mutant version) in trans from a second, compatible plasmid had little if any effect on the fusions (Figure 4A versus 4B, open versus closed circles). The four slopes are very similar, giving a combined average $\pm \mathrm{SE}$ of $51.7 \pm 1.7$ (i.e., $3.3 \% \mathrm{SE}$ ). This is inconsistent with trans-acting translational effects of C.PvuII protein, unlike the case of C.Eco72I [25].

\section{Assessing translational coupling of pvullC and pvullR}

Because coupling is sensitive to the proximity of the termination and start codons of the coupled genes [40], LacZ specific activity was measured in pvuIIR-lacZ fusions with the $p v u I I C$ stop codon at its native site (+20 nt relative to ATG of pvuIIR; Figure 2A) or moved $\sim 20$ nt downstream; no effect of this move was seen on translation of $p v u I I R-l a c Z$ fusions (not shown). We also generated stop codons 25 or $40 \mathrm{bp}$ upstream of the pvuIIR initiation codon (Figure $5 \mathrm{~A}$ ), in an otherwiseWT pvuIIR-lacZ translational fusion, and measured the LacZ activity (Figure 5B). These stop codons did not detectably affect translation in the pvuIIR reading frame.

Nevertheless, previous findings [41] and the results from the WT translational fusions indicate that the translation of $p v u I I R$ is very similar to that of $p v u I I C$ under several conditions, consistent with their translation being coupled. Accordingly we further tested this possibility.

\section{Frameshift mutation in pvullC reduces translation of pvullR}

We next determined the effects of mutations within pvuIIC, using our system in which transcription is

\begin{tabular}{|c|c|c|}
\hline A NTG $\rightarrow$ TNA & Sequence & RM System \\
\hline+20 & tgatggaacacgaaaATGagtcacccagatctaaaTAAattattagag & PvuII \\
\hline+14 & ccgaggagaattcagGTGccctttacttaTAGcattgaggcaa & SgrAI \\
\hline+11 & ggcagggtttaaaaaATGagcagggaTGAccaactcttt & SmaI \\
\hline+08 & aaggagacactcataATGaagatTGAtataacgga & BglII \\
\hline+05 & tggtggaagaaaaaaATGatTGAaagaaattta & LlaDI \\
\hline+05 & aggagattttaaagCATGacTAAaaatgttaag & Esp1396I \\
\hline+01 & ggagaataatcaggtATGAaatttgagt & SptAI \\
\hline+01 & tagggaggagaagagTTGAaaatttggt & $\mathrm{BcnI}$ \\
\hline-02 & ggagttattttgcTGATGccaaacccaa & AhdI \\
\hline-04 & aagggattaaaTAAtATGaatagatcaa & NmeSI \\
\hline-06 & cgaaaaggagTAAaaaATGggtaaatctg & MunI \\
\hline-11 & gatgagTAAtagatgcaATGaatagtttaa & SonORF4P \\
\hline -19 acaaaagaa & AgtgggggcaaattagaATGgaagtagaaa & BamHI \\
\hline
\end{tabular}

Figure 2 Relative Locations of C Terminators and R Initiators of Translation. Selected C.Pvull orthologs that are upstream of known or candidate restriction endonuclease genes were aligned via the endonuclease initiation codons to illustrate the range of relative positions. Names and gene boundaries are available at REBase [1]. Numbers at the left are center-to-center distances between the C gene termination codon and the R gene initiation codon. 


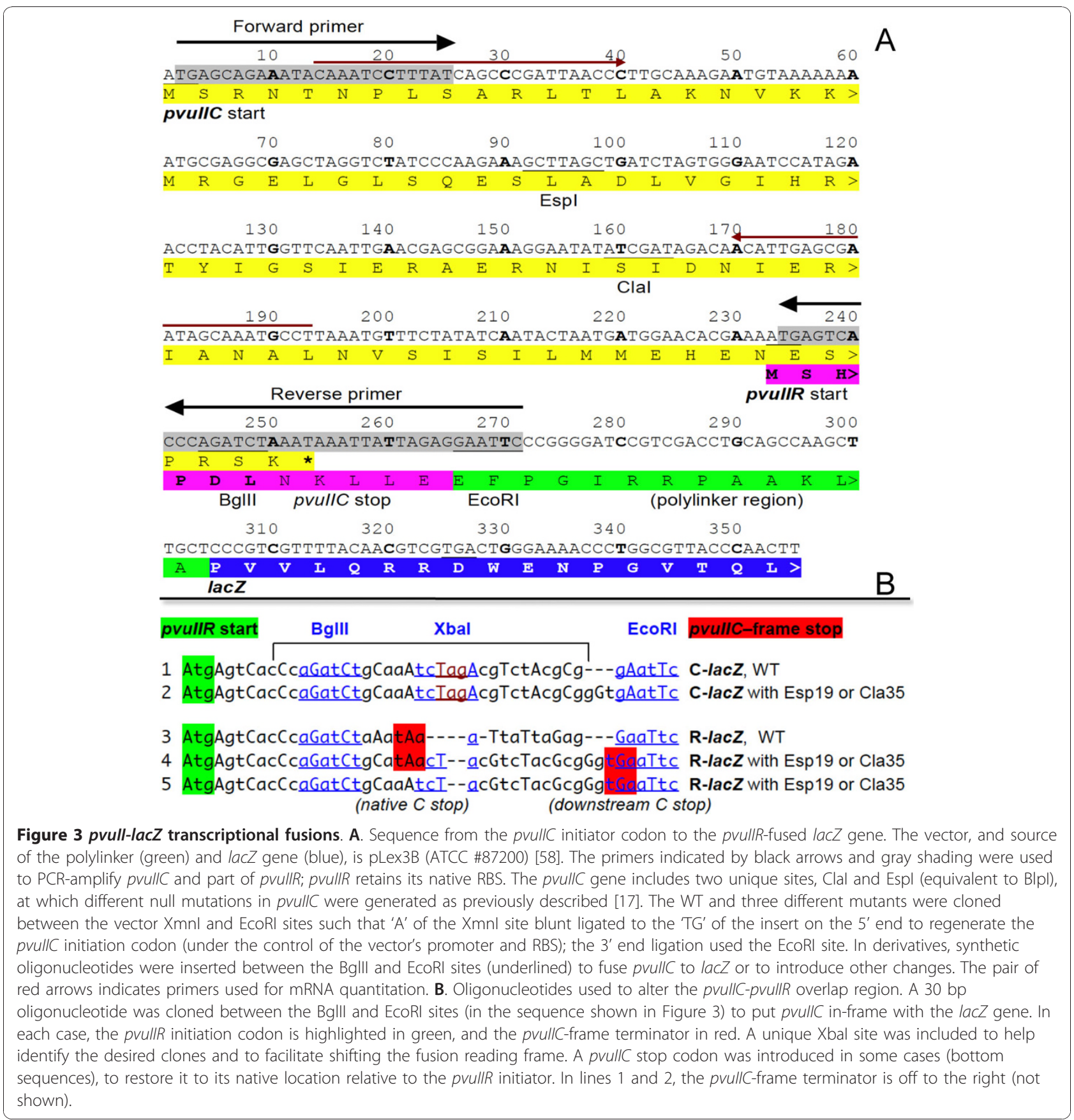

driven from a promoter unaffected by C.PvuII. WT C. PvuII was supplied from a compatible plasmid in trans. Figure $6 \mathrm{~A}$ is a correlogram, showing $\beta$-galactosidase expression, with the upstream ORF being WT or mutant pvuIIC, and lacZ is fused in the pvuIIC reading frame ( $x$-axis) or in the pvuIIR reading frame ( $y$-axis). The pvuIIC termination codon was, in all cases, in the native location. When pvuIIC was WT (up to the point of the fusion; see Figure 3B), translation was roughly equivalent in both reading frames.
Esp19 is an in-frame insertion of one leucine codon into $p v u I I C$, within the first helix of the DNA-binding helix-turn-helix motif [41] (see Figure 3A, and Additional file 1, Figure S1). Like the "WT" fusions, the pvuIIC-Esp19 fusions gave similar translational activity in both reading frames. Furthermore, the levels of translation were fairly similar to those when pvuIIC was WT.

Cla35 is a frameshift mutation in pvuIIC that results in a termination codon $\sim 70 \mathrm{nt}$ upstream of the normal 


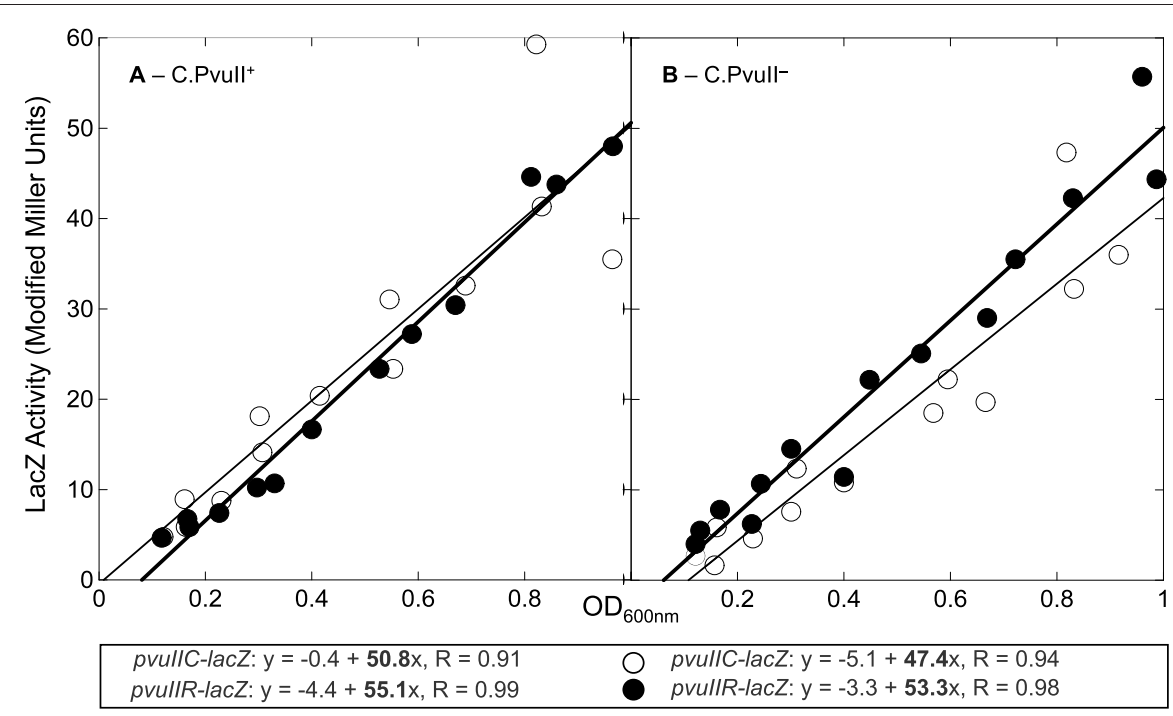

Figure 4 Expression of pvullC-lacZ and pvullR-lacZ translational fusions in the presence and absence of C.Pvull. Cultures of E. coli TOP10 were grown in exponential phase in defined rich medium containing IPTG, and samples were taken at several times for $\beta$-galactosidase assays. If the cells are in balanced growth, the plot of activity vs. culture density should be linear. The translational fusions were to pvullC (open circles) or pvullR (closed circles), and in both cases are transcribed from a C-independent vector promoter. The equations resulting from linear regression are shown. A. A compatible plasmid is providing active C.Pvull in trans. B. As in (A), except the plasmid is providing an inactive version of C.Pvull.

\section{A} $\begin{array}{ll}\text { WT: } & \text { TtaAatGttTctAtaTcaAtaCtaAtgAtgGaaCacGaaAatG } \\ \text { Mutants: TaaAatGttTctAtaTaAAtaCtaAtgAtgGaaCacGaaAatG } & 25 \mathrm{nt} \\ & 40 \mathrm{nt}\end{array}$

B

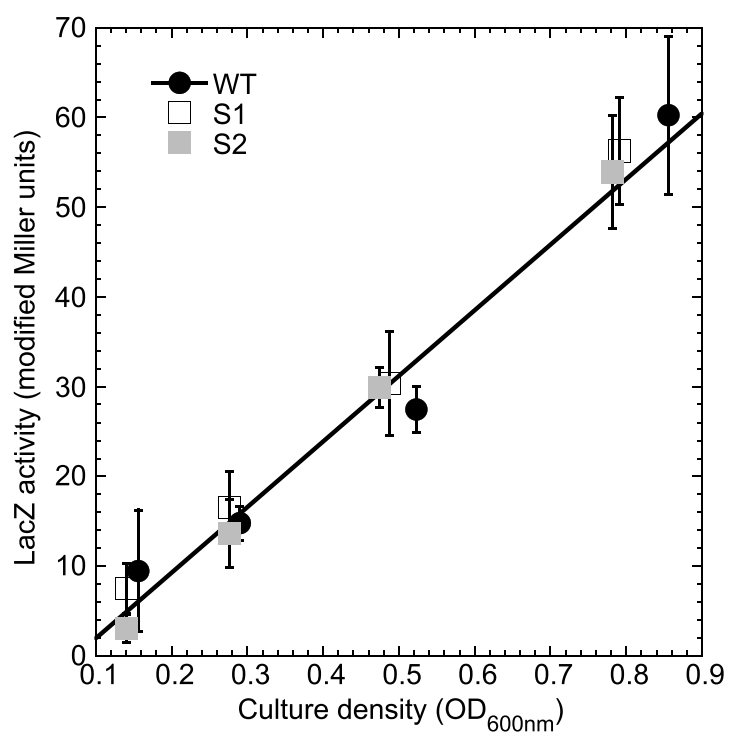

Figure 5 Stop codons created in pvulIC upstream of pvulIR-IacZ fusion initiation site. The native pvullC translation terminator is downstream of the pvullR initiation codon (see top line of Figure 2). A. To test for translational coupling, site-directed mutation was used to introduce pvullC terminators farther upstream. The pvullR RBS and intiation codon are indicated in green. The two introduced stop codons were in two independent clones. B. lacZ activity of the WT (filled circles) and the mutants (open squares have terminator indicated "S1" in part A; filled squares represent S2). The linear fit is to the WT data. 

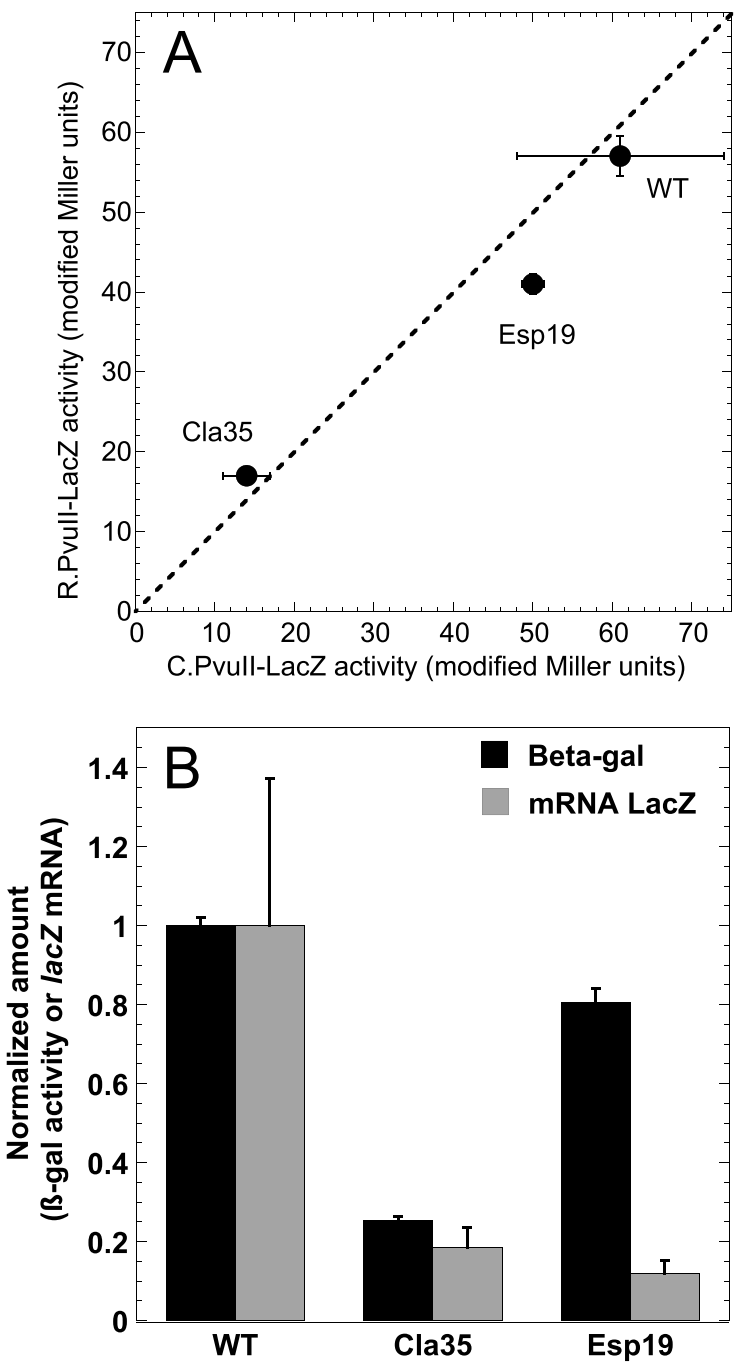

Figure 6 Effects of pvullC mutation. A. Comparison of pvullC and pvullR translation with WT and mutant variants of pvullC. The slopes from triplicate experiments such as that shown in Figure 4 are plotted, showing standard errors (where bars are not visible, errors were smaller than the symbol). In this correlogram, activity from the pvullC-lacZ translational fusion is shown on the $x$-axis, and that from the pvullR-lacZ fusion of the same mutant is on the $y$-axis; if the two fusions for a given variant have equal translation, the point would fall on the dotted line. B. Effects of mutation on mRNA levels and translation activity of pvullR-lacZ fusions. Reporter pvullR fusions with WT pvullC upstream, or with the Cla35 (frameshift) or Esp19 (inframe) pvullC mutations, were grown in triplicate. Real-time RT-PCR was carried out as described in Methods, using the SYBR green method [60] and primers specific to lacZ. Quantitation was based on a standard curve with normalization to recA mRNA. Amounts of mRNA (gray bars) are normalized to the level in the strain carrying WT pvullC. The black bars indicate lacZ activity measurements in the same cultures, measured as shown in Figure 4 and normalized to the WT value. Standard errors are shown. stop codon [17] (see Figure 3A, and Additional file 1, Figure S1). The new stop codon is UAG followed by A, which in one in vivo assay system gives a termination rate of about $50 \%$ [42]. This mutation led to a roughly fivefold decrease in $\beta$-galactosidase expression, relative to the WT fusions, when lacZ was fused in either reading frame. This effect appears to be due to transcriptional polarity (see below), but the important point here is that pvuIIR-and pvuIIC-frame translation changed in parallel.

\section{Quantitative real-time RT-PCR (QRT-PCR) reveals transcriptional polarity}

The parallel fivefold drop in pvuIIC and pvuIIR translation in the pvuIIC-Cla35 frameshift mutant (Figure 6A) could reflect premature translation termination leading to premature transcript termination $[43,44]$. To test this, relative lac $Z$ mRNA levels were determined by QRT-PCR for the WT and both mutant pvuIIR-lacZ fusion strains (see lines 3-5 in Figure 3B). In the case of Cla35, the amount of lacZ mRNA dropped by the same fivefold amount as did translation (Figure 6B), consistent with transcriptional polarity (and, for that matter, with coupling between the rates of pvuIIC and pvuIIR translation).

However, surprisingly, the levels of lacZ mRNA dropped by about the same extent in the strains bearing an in-frame single-codon insertion (Esp19; Figure 6B). The junction sequences of the Cla35 and Esp19 fusions are identical (line 5, Figure 3B). Esp19 only minimally changed the level of pvuIIR-lacZ translation (Figure 6), but this implies that it substantially increased the apparent translational initiation at the downstream $p v u I I R$ initiator, relative to WT, as there is only about an eighth as much mRNA (gray bars in Figure 6B).

\section{Putative hairpins upstream of pvullR have no obvious effect on its translation}

The pvuIIR gene is preceded by two predicted, alternative hairpins ([9]; Figure 7A). Previous primer extension studies [9] were consistent with the presence of the upstream hairpin (left in Figure 7A), as a termination product was seen immediately adjacent to the predicted stem (red circles). These hairpins might regulate translation of pvuIIR, because the downstream hairpin (right side of Figure 7A) would occlude the RBS. Occlusion of an RBS by mRNA secondary structure is a major determinant of translational initiation rates [45-49].

If this model is correct, altering Arm 2 (orange-shaded sequence in Figure 7A) should disrupt both hairpins and 


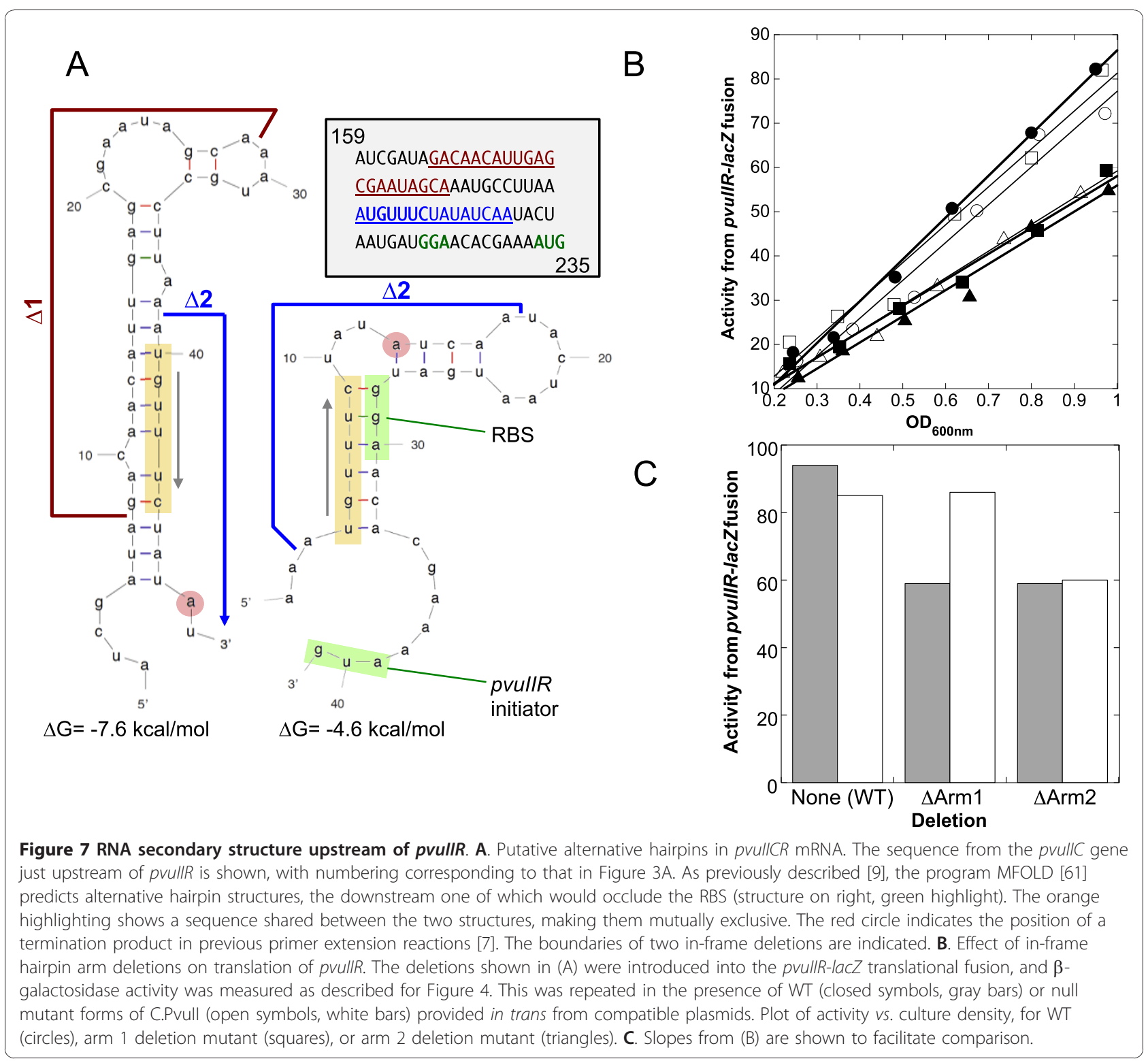

thus increase pvuIIR translation, while altering Arm 1 should disrupt the $5^{\prime}$ hairpin, promote formation of the 3 ' hairpin, and thus decrease translation of pvuIIR. We made an in-frame deletion of Arm 2 from the WT construct (" $\Delta 2$ " in Figure 7A, and Additional file 1, Figure S1) and tested the effects on a pvuIIR-lacZ translational fusion (Figure 7B). Rather than the predicted increase in translation, this deletion reduced expression somewhat. [Supplying WT C.PvuII in trans had no effect (as expected, since a C-independent promoter was being used).] In contrast, the $\Delta$ Arm 1 deletion (Figure $7 \mathrm{~A}$, and Additional file 1, Figure S1) was predicted to reduce $p v u I I R-l a c Z$ translation, but did so only mildly, and even then only in the presence of WT C.PvuII supplied in trans (Figure 7C).

\section{Discussion}

In bacteria such as $E$ coli, genes are often transcribed into polycistronic mRNAs [50]. Ribosomes from an upstream gene can reinitiate translation at the next initiator in a process called translational coupling. The extent of dependence on reinitiation (as opposed to initiation by newly-bound ribosomes) varies, but tends to vary inversely with the distance between the termination and reinitiation codon [51]. In most polycistronic operons, termination codons are close to the initiation codon of the downstream gene; in many cases they even overlap [37], as in the BcnI and AhdI R-M systems (Figure $2 \mathrm{~A}$ ). A high degree of coupling results in coordinated expression of the genes, as illustrated by the gal operon [43,52]. 
In $\mathrm{RM}$ systems that rely on upstream $\mathrm{C}$ genes to mediate the delay in REase expression, allowing the MTase time to protect a new host's chromosome [28]; translational coupling could play an important role in the regulatory design. The $\mathrm{C}$ and $\mathrm{R}$ genes of another C-activated RM system, Esp1396I, are in fact translationally coupled [44]. Furthermore, as shown in Figure 1 , translation of $p v u I I C$ from the early $p v u I I C R$ transcripts relies on a poor RBS (a feature not shared by most of the $\mathrm{C}$ genes). Translational coupling of pvuIIR to $p v u I I C$ would ensure that very little R.PvuII is made from the early transcripts (though in rare cases transcripts lacking RBSs in the leader can still be translated efficiently [53]). Once C.PvuII begins to accumulate, it not only generates a positive feedback loop by activating a second promoter upstream of $p v u I I C$, but translation of these later transcripts should be much more efficient as they are leaderless [7] and do not rely on the weak RBS.

However our evidence provides no consistent evidence that the translation of $p v u I I R$ is coupled to that of pvuIIC. Most significantly, moving the pvuIIC termination codon in either direction relative to the $p v u I I R$ initiator (Figures 3B, 5) had no apparent effect. In contrast, coupled genes are quite sensitive to the stop-start codon spacing (e.g., see Additional file 1, Figure S2, replotted from data in [40]).

This lack of coupling is consistent with previous work from our laboratory. We had demonstrated a sharp decrease in the expression of pvuIIR in each of four pvuIIC null mutants [17], including two in-frame (EspI) and two frameshift (ClaI) mutants (two of which were used in the current study). These mutants showed greatly-impaired restriction of infection by unmethylated bacteriophage $\lambda$, or of transformation by plasmid DNA, and the in vitro R.PvuII activity was $\sim 10^{4}$-fold less than in strains that carried the intact parental plasmid. Providing pvuIIC in trans had no effect on the WT strain, but providing it to any of the pvuIIC mutants resulted in full restoration of in vivo or in vitro R.PvulI activity. However boosting transcription of frameshift mutants, that terminate translation $\sim 70 \mathrm{nt}$ upstream of the pvuIIR initiation codon (Figure 3A, and Additional file 1, Figure $\mathrm{S} 1$ ), would not have restored a flow of translating ribosomes to the pvuIIR initiator, so these results conflict with coupling.

$C$ proteins themselves can have regulatory effects at the translational level. In the Eco72I RM system [25], providing C.Eco72I in trans to eco72IR-lacZ translational fusions restored REase gene expression even when the upstream eco72IC gene included a frameshift mutation. However, in the case of PvuII, neither pvuIIClacZ nor pvuIIR-lacZ translational fusions showed substantial effects of supplying C.PvuII in trans.
Hairpins in the RNA that occlude RBSs can reduce translation initiation [45,47-49], though initiating ribosomes have the capacity to unfold mRNA [54] and may also be prepositioned to slide into place when an RNA hairpin spontaneously unfolds [46]. In-frame deletions in $p v u I C$, that would affect predicted alternative hairpins upstream of $p v u I I R$ and thus alter the availability of the pvuIIR RBS (Figure 7A), had no major effect (Figure $7 \mathrm{~B}, \mathrm{C}$ ). However, the hairpins might nonetheless reduce the entry of new ribosomes at the pvuIIR RBS, while not affecting progress of translating ribosomes. Searching for potential RBS-occluding hairpins in other $\mathrm{C}$-dependent $\mathrm{R}-\mathrm{M}$ systems showed that 9/11 had such hairpins with $\Delta G$ values $\leq-4.0 \mathrm{kcal} / \mathrm{mol}$ (Additional file 1, Figure S3). For comparison, the equivalent PvuII hairpin has a predicted $\Delta G$ of $-4.6 \mathrm{kcal} / \mathrm{mol}$.

\section{Conclusion}

The genes for RM systems are often associated with mobile genetic elements, and temporal control is critical following the entry of these genes into a new cell, to avoid restriction of the host's chromosome. The role of translation-level regulation in this process has not been well studied. In examining the PvuII RM system, we found that translation of the downstream REase gene ( $p v u I I R)$ is independent of that of the upstream gene for the autogenous activator/repressor ( $p v u I I C)$, at least under the conditions used. This independence was despite the overlapping genes and the presence of putative RNA hairpins involving the pvuIIR RBS. This suggests that the temporal control of PvuII transcription [28], together with the repair capabilities of the bacteria [55-57], is sufficiently robust to protect the new host cell following PvuII gene transfer.

\section{Methods}

\section{Cloning and generation of mutants}

Table 1 and Additional file 1, Table S1 show, respectively, the plasmids and oligonucleotides that were used in this study. The Cla and Esp mutants of pvuIIC were generated previously by this lab [17]. pPvuRM3.4 contains the WT PvuII R-M system as a $3.4 \mathrm{~kb}$ fragment in vector pBR322 [12], and this R-M system includes two unique enzyme sites in the pvuIIC ORF, ClaI and EspI (currently available as the isoschizomer BlpI) (see Figure 3A, and Additional file 1, Figure S1). At the ClaI site, filling in the 5' extensions with Klenow polymerase or digestion using mung bean nuclease, followed by religation, generates frameshift mutations. EspI yields a 3-bp overhang (GC/TNAGC), so fill-in or digestion creates an in-frame mutation [17].

For this study, DNAs from WT pvuIIC, mutant Esp19 (with insertion of a leucine codon) and mutant Cla35 (frameshift insertion), were purified using the QIAprep plasmid kit (Qiagen, Germantown, MD). Oligonucleotide primers were purchased from Integrated DNA 
Table 1 Plasmids used in this study

\begin{tabular}{lll}
\hline Name & Relevant Feature $(\mathbf{s})$ & Reference \\
\hline pDK200 & WT pvullC gene with its own promoter, $\triangle$ pvullM, & {$[7]$} \\
pDK201 & $p$ pvullR; Tet ${ }^{R}$, pACYC177 & {$[7]$} \\
pDK201-Esp33 & pDK200 with pvullC-Esp19 in-frame insertion & This study \\
pDK201-Cla35 & pDK200 with pvullC-Esp33 in-frame insertion & This study \\
pPvullRM3.4 & pDK200 with pvullC-Cla35 frameshift mutation & {$[12]$} \\
pPvullRM3.4- Esp19 & WT Pvull R-M system; Amp ${ }^{R}$, pBR322 & {$[17]$} \\
pLex3B & pPvullRM3.4 with pvullC-Esp19 in-frame insertion & {$[58]$} \\
& Plasmid from ATCC (\#87200) used to create translational fusions, to lacZ; Amp ${ }^{R}$, pMB1 origin & \\
\hline
\end{tabular}

technology company (IDT, Coralville, IA). The amplified region began upstream of the pvuIIC ATG initiator and ended a few codons into pvuIIR (including the entire overlap between $p v u I I C$ and $p v u I I R, \sim 285 \mathrm{bp})$. High fidelity Pfx polymerase (New England Biolabs, Ipswich, MA) was used to amplify the fragment, which was then purified using a Qiagen gel extraction kit.

The amplified fragments were cloned into TOPO 2.1 vector (Invitrogen, Carlsbad, CA), and ligation products were used to transform TOP-10 chemically competent E. coli (Invitrogen). Transformants were plated onto LB agar with $100 \mu \mathrm{g} / \mathrm{ml}$ ampicillin. Colonies were inoculated into LB broth with appropriate antibiotics, and clones demonstrating the expected restriction pattern were confirmed by sequencing.

\section{LacZ translational fusions}

Inserts from sequence confirmed clones in TOPO 2.1 were again amplified using a second set of primers (black arrows in Figure 3A). The secondary amplification began with 'TG' of the ATG initiator of pvuIIC at the 5 ' end, and extended into pvuIIR (downstream of the $p v u I I C$ termination codon). An EcoRI site was added to the 3' end of the insert. Plasmid pPvuIIRM3.4 carries the WT PvuII RM system in vector pBR322 [12], and $p v u I I C$ contains unique restriction sites (ClaI and EspI/BlpI) that were used to generate mutants [17] (Figure 3A). Wild type and mutant versions of pPvuIIRM3.4 were used as templates. The amplified segments were cloned in-frame with lac $Z$ in vector pLEX3B [58]. PCR amplification used high fidelity Pfx polymerase (New England Biolabs). The EcoRI digested fragment was purified by electrophoresis and the Qiagen gel extraction kit. A similar protocol was followed for all three mutants and the wild type.

We prepared fusions in which the pvuIIC initiation codon was the optimal distance from the RBS of pLEX3B (ATCC \# 87200, ATCC, Manassas, VA). Insert DNA was cloned between the XmnI and EcoRI site of the PLEX3B vector, such that on the 5' end 'A' of the $\mathrm{XmnI}$ site was blunt ligated to the 'TG' of the insert; the 3 ' end ligation used the EcoRI site. To facilitate converting these clones from pvuIIC to pvuIIR being inframe with lacZ, a 30 bp oligonucleotide was acquired with a BglII site at the 5' end (sense strand) and EcoRI at the 3 ' end (see Figure 3B). In the middle was a unique $\mathrm{XbaI}$ site to facilitate identification of the desired clones. This 30 mer duplex was cloned between the BglII and EcoRI sites of the pvuIIR-lac Z fusions (see Figure 3B).

The WT pvuIIC translational fusion contains the full ORF and few codons from pvuIIR in-frame with lacZ. We removed the stop codon from the pvuIIC ORF. In the Cla35 frameshift mutant of pvuIIC, lacZ is in-frame with the shifted $p v u I I C$ reading frame (though there are intervening nonsense codons). Two nucleotides (AG) were deleted to shift the frame, such that pvuIIR was inframe with $l a c Z$. This shifted the stop codon for $p v u I I C$ by few codons relative to the pvuIIR initiator, so we used site directed mutagenesis to restore the stop codon to its original position by substitution. Primers (IDT) were designed for this purpose, to function with the Stratagene QuickII site-directed mutagenesis protocol and kit (Agilent, Santa Clara, CA).

Ligation products were used for transformation as described above, except that IPTG $(1 \mathrm{mM})$, and X-gal (bromo-chloro-indolyl-galactopyranoside, $40 \mu \mathrm{g} / \mathrm{ml}$ ) were also added to the agar. Transformants that turned blue were patched and also inoculated into LB broth with the appropriate antibiotics. Putative lac $Z$ translational fusions were isolated and confirmed by restriction-digestion as well as colony PCR. Clones that demonstrated the desired restriction pattern were confirmed by sequencing.

\section{Hairpin mutants}

We prepared in-frame arm 1 and arm 2 deletions in the predicted hairpins (Figure 7A) using site-directed mutagenesis kit and protocols as described above. Again this set was confirmed by sequencing (MWG, High Point, NC).

\section{Beta-galactosidase assays}

We measured hydrolysis of the substrate $o$-nitrophenyl$\beta$-D-galactoside (ONPG). Overnight cultures were 
grown at $37^{\circ} \mathrm{C}$ in $\mathrm{MOPS}$ rich defined medium (TEKNOVA, Hollister, CA), in the presence of tetracycline $(10 \mu \mathrm{g} / \mathrm{ml})$ and the inducer IPTG $(1 \mathrm{mM})$. This culture was diluted 1:100 into the same medium, without tetracycline, and grown to exponential phase. Samples were collected at regular intervals and the optical density (OD) at $600 \mathrm{~nm}$ was measured for every $1 \mathrm{ml}$ sample. Two drops of chloroform and one drop of $0.1 \%$ SDS were added, and the sample vortexed for $10 \mathrm{~s}$ to open the cells. Samples were placed in a $28^{\circ} \mathrm{C}$ water bath for $5 \mathrm{~min}$, and $200 \mu \mathrm{l} \mathrm{ONPG}(4 \mathrm{mg} / \mathrm{ml})$ were added. Reactions were stopped with $500 \mu \mathrm{l} 1 \mathrm{M}$ $\mathrm{Na}_{2} \mathrm{CO}_{3}$, and $\mathrm{OD}_{420 \mathrm{~nm}}$ was determined. The formula of Miller [59] was used to calculate units of $\beta$-galactosidase. Miller units were plotted against the culture $\mathrm{OD}_{600 \mathrm{~nm}}$. The slopes from linear regression indicate relative specific activity; linearity indicates that the culture was in balanced growth.

\section{RNA isolation and quantitation}

Cultures were grown as described above, to an $\mathrm{OD}_{600 \mathrm{~nm}}$ of $\sim 0.3$, in the presence of IPTG $(1 \mathrm{mM})$. Samples were taken from the flasks and directly added to two volumes of RNA stabilization buffer (RNA Protect Bacteria Reagent, Qiagen, Valencia, CA). Samples were mixed and left at room temperature for $10 \mathrm{~min}$. The RNeasy miniprep kit (Qiagen) was used to isolate total RNA. Cells in stabilization buffer were harvested by centrifugation at $4^{\circ}$ $\mathrm{C}$ for $15 \mathrm{~min}$ at 5,000 rpm. Pellets were resuspended in $1 \times$ TE buffer containing lysozyme $(400 \mu \mathrm{g} / \mathrm{ml})$ after removing the supernatant. Ethyl alcohol was added to precipitate the RNA, which was then dissolved and loaded onto the columns. Following column washing and elution, RNA was treated with RQ1 RNAse-free DNAse (Promega, Madison, WI) to remove DNA. cDNA was synthesized using total RNA as template, random hexamers (Invitrogen), and ImPromII reverse transcriptase (Promega). The random primers were annealed at $25^{\circ} \mathrm{C}$ for $5 \mathrm{~min}$, and the first strand was then extended at $42^{\circ} \mathrm{C}$ for $1 \mathrm{~h}$. The reverse transcriptase was then inactivated by heating at $70^{\circ} \mathrm{C}$ for $1 \mathrm{~h}$.

Red arrows in Figure 3A indicate the primer pair used to quantitate pvuIIC cDNA. Dilutions of cDNA were tested to determine the maximally-efficient concentration for amplification, and also the efficiency of each primer pair. recA expression was also measured, to provide an internal baseline. Cycle threshold $(\mathrm{Ct})$ values were determined using a Roche Light Cycler with SYBR Green. Melting curve analysis was used to confirm the formation of specific products. The standard curve method was used to determine the relative amounts of mRNA, which were normalized to $\operatorname{rec} A$ [60].

\section{Additional material}

\begin{abstract}
Additional file 1: Supplemental Information. Figure S1. Location of mutations relative to features of C.Pvull. The amino acid sequence of C.Pvull is shown in single-letter code (GenBank AAA96335.1). The DNAbinding helix-turn-helix motif contains the Espl (Blpl) site; fill-in or resection followed by religation duplicates or removes the leucine in the "SLA" sequence. Orange shading indicates the subunit interface, from comparison to the crystal structure for an orthologous C protein [20]. This interface spans the Clal site used to generate frameshift mutations. The two in-frame deletions of predicted RNA hairpin elements (see Figure $7 A$ ) are indicated as $\Delta 1$ and $\Delta 2$. The position of the alternate reading frame pvullR initiation codon is indicated. Figure S2. Effects of distance between termination and initiation codons on translational reinitiation. This is a replotting of data from [40]. The lac $Z$ gene was introduced into $E$. coli with varied spacing between the lacZ initiation codon and the terminator for the upstream ORF. Figure S3. Putative RNA hairpins upstream of REase gene initiation codon in selected C-dependent R-M systems. C-dependent R-M systems, from among those shown in Figure 2, were analyzed for potential hairpin structures upstream of the REase gene initiation codon. The $40 \mathrm{nt}$ upstream of each initiator were submitted to MFOLD [61], and the most stable structure returned in each case is shown. The number in parentheses is the predicted $\Delta \mathrm{G}$ of folding, in $\mathrm{kcal} / \mathrm{mol}$. The Esp1396l structure may be further stabilized by its GNRA loop [62].The initiator codon and predicted RBS are highlighted in green. Secondary structures are shown for comparison, whether or not they are likely to be present a significant fraction of the time.
\end{abstract}

\section{Acknowledgements}

We thank Drs. Robert Lintner and Iwona Mruk for help with the real-time QRT$P C R$, and Dr. Mruk for critically reviewing the manuscript. MKK was supported in part by graduate stipends from the University of Toledo and the Department of Medical Microbiology \& Immunology. This material is based upon work supported by the US National Science Foundation under Grant No. MCB-0964728.

\section{Author details}

${ }^{1}$ Department of Medical Microbiology and Immunology, University of Toledo Health Science Campus, 3100 Transverse Drive, Toledo, OH 43614-2598, USA. ${ }^{2}$ Program in Bioinformatics and Proteomics/Genomics, University of Toledo Health Science Campus, 3100 Transverse Drive, Toledo, OH 43614-2598, USA.

\section{Authors' contributions}

MK carried out the strain constructions and experimental analysis, participated in the experimental design, and drafted the manuscript. RB conceived of the study, participated in its design and coordination, helped to draft the manuscript, and generated the figures. Both authors read and approved the final manuscript.

Received: 2 July 2010 Accepted: 19 November 2010

Published: 19 November 2010

\section{References}

1. Roberts RJ, Vincze T, Posfai J, Macelis D: REBASE-a database for DNA restriction and modification: enzymes, genes and genomes. Nucleic Acids Res 2010, 38 Database: D234-236.

2. Releigh EA, Brooks JE: Restriction Modification systems: where they are and what they do. Chapman \& Hall, New York, N.Y; 1998.

3. Kobayashi I: Behavior of restriction-modification systems as selfish mobile elements and their impact on genome evolution. Nucleic Acids Res 2001, 29(18):3742-3756.

4. Ichige A, Kobayashi I: Stability of EcoRI restriction-modification enzymes in vivo differentiates the EcoRI restriction-modification system from other postsegregational cell killing systems. J Bacteriol 2005, 187(19):6612-6621.

5. Nakayama $Y$, Kobayashi I: Restriction-modification gene complexes as selfish gene entities: roles of a regulatory system in their establishment, 
maintenance, and apoptotic mutual exclusion. Proc Natl Acad Sci USA 1998, 95(11):6442-6447.

6. Roberts RJ, Belfort M, Bestor T, Bhagwat AS, Bickle TA, Bitinaite J, Blumenthal RM, Degtyarev S, Dryden DT, Dybvig K, et al: A nomenclature for restriction enzymes, DNA methyltransferases, homing endonucleases and their genes. Nucleic Acids Res 2003, 31(7):1805-1812.

7. Knowle D, Lintner RE, Touma YM, Blumenthal RM: Nature of the promoter activated by C.Pvull, an unusual regulatory protein conserved among restriction-modification systems. J Bacterio/ 2005, 187(2):488-497.

8. Naderer M, Brust JR, Knowle D, Blumenthal RM: Mobility of a restrictionmodification system revealed by its genetic contexts in three hosts. J Bacteriol 2002, 184(9):2411-2419.

9. Vijesurier RM, Carlock L, Blumenthal RM, Dunbar JC: Role and mechanism of action of $C$. Pvull, a regulatory protein conserved among restrictionmodification systems. J Bacterio/ 2000, 182(2):477-487.

10. Furuta Y, Abe K, Kobayashi I: Genome comparison and context analysis reveals putative mobile forms of restriction-modification systems and related rearrangements. Nucleic Acids Res 2010, 38(7):2428-2443.

11. Gingeras TR, Greenough L, Schildkraut I, Roberts RJ: Two new restriction endonucleases from Proteus vulgaris. Nucleic Acids Res 1981, 9(18):4525-4536

12. Blumenthal RM, Gregory SA, Cooperider JS: Cloning of a restrictionmodification system from Proteus vulgaris and its use in analyzing a methylase-sensitive phenotype in Escherichia coli. J Bacteriol 1985, 164(2):501-509.

13. Butkus V, Klimasauskas S, Petrauskiene L, Maneliene Z, Lebionka A, Janulaitis A: Interaction of Alul, Cfr6l and Pvull restriction-modification enzymes with substrates containing either N4-methylcytosine or 5-methylcytosine. Biochim Biophys Acta 1987, 909(3):201-207.

14. Rice MR, Blumenthal RM: Recognition of native DNA methylation by the Pvull restriction endonuclease. Nucleic Acids Res 2000, 28(16):3143-3150.

15. Rice MR, Koons MD, Blumenthal RM: Substrate recognition by the Pvu II endonuclease: binding and cleavage of CAG5mCTG sites. Nucleic Acids Res 1999, 27(4):1032-1038.

16. Brooks JE, Nathan PD, Landry D, Sznyter LA, Waite-Rees P, Ives CL, Moran LS, Slatko BE, Benner JS: Characterization of the cloned BamHI restriction modification system: its nucleotide sequence, properties of the methylase, and expression in heterologous hosts. Nucleic Acids Res 1991, 19(4):841-850.

17. Tao T, Bourne JC, Blumenthal RM: A family of regulatory genes associated with type II restriction-modification systems. J Bacterio/ 1991, 173(4):1367-1375.

18. Sorokin V, Severinov K, Gelfand MS: Systematic prediction of control proteins and their DNA binding sites. Nucleic Acids Res 2009, 37(2):441-451

19. Sawaya MR, Zhu Z, Mersha F, Chan SH, Dabur R, Xu SY, Balendiran GK: Crystal structure of the restriction-modification system control element C.BCll and mapping of its binding site. Structure 2005, 13(12):1837-1847.

20. McGeehan JE, Streeter SD, Papapanagiotou I, Fox GC, Kneale GG: Highresolution crystal structure of the restriction-modification controller protein C.Ahdl from Aeromonas hydrophila. J Mol Biol 2005, 346(3):689-701.

21. Ball N, Streeter SD, Kneale GG, McGeehan JE: Structure of the restrictionmodification controller protein C.Esp1396l. Acta Crystallogr D Biol Crystallogr 2009, 65(Pt 9):900-905.

22. McGeehan JE, Streeter SD, Thresh SJ, Ball N, Ravelli RB, Kneale GG: Structural analysis of the genetic switch that regulates the expression of restriction-modification genes. Nucleic Acids Res 2008, 36(14):4778-4787.

23. McGeehan JE, Papapanagiotou I, Streeter SD, Kneale GG: Cooperative binding of the C.Ahdl controller protein to the $\mathrm{C} / \mathrm{R}$ promoter and its role in endonuclease gene expression. J Mol Biol 2006, 358(2):523-531.

24. Mruk I, Rajesh P, Blumenthal RM: Regulatory circuit based on autogenous activation-repression: roles of C-boxes and spacer sequences in control of the Pvull restriction-modification system. Nucleic Acids Res 2007, 35(20):6935-6952.

25. Rimseliene $R$, Vaisvila $R$, Janulaitis A: The eco72IC gene specifies a transacting factor which influences expression of both DNA methyltransferase and endonuclease from the Eco72l restrictionmodification system. Gene 1995, 157(1-2):217-219.

26. Semenova E, Minakhin L, Bogdanova E, Nagornykh M, Vasilov A, Heyduk T, Solonin A, Zakharova M, Severinov K: Transcription regulation of the
EcoRV restriction-modification system. Nucleic Acids Res 2005, 33(21):6942-6951.

27. Bogdanova E, Zakharova M, Streeter S, Taylor J, Heyduk T, Kneale G, Severinov K: Transcription regulation of restriction-modification system Esp1396l. Nucleic Acids Res 2009, 37(10):3354-3366.

28. Mruk I, Blumenthal RM: Real-time kinetics of restriction-modification gene expression after entry into a new host cell. Nucleic Acids Res 2008 36:2581-2593.

29. Calvin Koons MD, Blumenthal RM: Characterization of pPvu1, the autonomous plasmid from Proteus vulgaris that carries the genes of the Pvull restriction-modification system. Gene 1995, 157(1-2):73-79.

30. Shultzaberger RK, Bucheimer RE, Rudd KE, Schneider TD: Anatomy of Escherichia coli ribosome binding sites. J Mol Biol 2001, 313(1):215-228.

31. Jin H, Zhao Q, Gonzalez de Valdivia El, Ardell DH, Stenstrom M, Isaksson LA: Influences on gene expression in vivo by a Shine-Dalgarno sequence. Mol Microbiol 2006, 60(2):480-492

32. Nakagawa S, Niimura Y, Miura K, Gojobori T: Dynamic evolution of translation initiation mechanisms in prokaryotes. Proc Natl Acad Sci USA 2010, 107(14):6382-6387.

33. Proshkin S, Rahmouni AR, Mironov A, Nudler E: Cooperation between translating ribosomes and RNA polymerase in transcription elongation. Science 2010, 328(5977):504-508.

34. Moll I, Hirokawa G, Kiel MC, Kaji A, Blasi U: Translation initiation with $70 \mathrm{~S}$ ribosomes: an alternative pathway for leaderless mRNAs. Nucleic Acids Res 2004, 32(11):3354-3363.

35. O'Donnell SM, Janssen GR: Leaderless mRNAs bind $70 \mathrm{~S}$ ribosomes more strongly than $30 \mathrm{~S}$ ribosomal subunits in Escherichia coli. J Bacterio/ 2002, 184(23):6730-6733.

36. Udagawa T, Shimizu Y, Ueda T: Evidence for the translation initiation of leaderless mRNAs by the intact $70 \mathrm{~S}$ ribosome without its dissociation into subunits in eubacteria. J Biol Chem 2004, 279(10):8539-8546.

37. Oppenheim DS, Yanofsky C: Translational coupling during expression of the tryptophan operon of Escherichia coli. Genetics 1980, 95(4):785-795.

38. Rex G, Surin B, Besse G, Schneppe B, McCarthy JE: The mechanism of translational coupling in Escherichia coli. Higher order structure in the atpHA mRNA acts as a conformational switch regulating the access of de novo initiating ribosomes. J Biol Chem 1994, 269(27):18118-18127.

39. Inokuchi $Y$, Hirashima $A$, Sekine $Y$, Janosi $L$, Kaji $A$ : Role of ribosome recycling factor (RRF) in translational coupling. EMBO J 2000, 19(14):3788-3798.

40. van de Guchte M, Kok J, Venema G: Distance-dependent translational coupling and interference in Lactococcus lactis. Mol Gen Genet 1991, 227(1):65-71.

41. Tao T, Blumenthal RM: Sequence and characterization of pvullR, the Pvull endonuclease gene, and of pvullC, its regulatory gene. J Bacteriol 1992, 174(10):3395-3398

42. Poole ES, Brown CM, Tate WP: The identity of the base following the stop codon determines the efficiency of in vivo translational termination in Escherichia coli. EMBO J 1995, 14(1):151-158.

43. Schumperli D, Howard BH, Rosenberg M: Efficient expression of Escherichia coli galactokinase gene in mammalian cells. Proc Natl Acad Sci USA 1982, 79(2):257-261.

44. Cesnaviciene E, Mitkaite G, Stankevicius K, Janulaitis A, Lubys A: Esp1396I restriction-modification system: structural organization and mode of regulation. Nucleic Acids Res 2003, 31(2):743-749.

45. de Smit MH, van Duin J: Secondary structure of the ribosome binding site determines translational efficiency: a quantitative analysis. Proc Nat Acad Sci USA 1990, 87(19):7668-7672.

46. de Smit MH, van Duin J: Translational standby sites: how ribosomes may deal with the rapid folding kinetics of mRNA. J Mol Biol 2003, 331(4):737-743.

47. Kozak M: Regulation of translation via mRNA structure in prokaryotes and eukaryotes. Gene 2005, 361:13-37.

48. Kudla G, Murray AW, Tollervey D, Plotkin JB: Coding-sequence determinants of gene expression in Escherichia coli. Science 2009, 324(5924):255-258

49. Seo SW, Yang J, Jung GY: Quantitative correlation between mRNA secondary structure around the region downstream of the initiation codon and translational efficiency in Escherichia coli. Biotechnol Bioeng 2009, 104(3):611-616. 
50. Mendoza-Vargas A, Olvera L, Olvera M, Grande R, Vega-Alvarado L, Taboada B, Jimenez-Jacinto V, Salgado H, Juarez K, Contreras-Moreira B, et al: Genome-wide identification of transcription start sites, promoters and transcription factor binding sites in E. coli. PLoS One 2009, 4(10): e7526..

51. Schoner BE, Belagaje RM, Schoner RG: Translation of a synthetic twocistron mRNA in Escherichia coli. Proc Natl Acad Sci USA 1986, 83(22):8506-8510.

52. Schumperli D, McKenney K, Sobieski DA, Rosenberg M: Translational coupling at an intercistronic boundary of the Escherichia coli galactose operon. Cell 1982, 30(3):865-871.

53. Skorski P, Leroy P, Fayet O, Dreyfus M, Hermann-Le Denmat S: The highly efficient translation initiation region from the Escherichia coli rpsA gene lacks a shine-dalgarno element. J Bacteriol 2006, 188(17):6277-6285.

54. Studer SM, Joseph S: Unfolding of mRNA secondary structure by the bacterial translation initiation complex. Mol Cell 2006, 22(1):105-115.

55. Heitman J, Ivanenko T, Kiss A: DNA nicks inflicted by restriction endonucleases are repaired by a RecA- and RecB-dependent pathway in Escherichia coli. Mol Microbiol 1999, 33(6):1141-1151.

56. Heitman J, Zinder ND, Model P: Repair of the Escherichia coli chromosome after in vivo scission by the EcoRl endonuclease. Proc Natl Acad Sci USA 1989, 86(7):2281-2285.

57. Chayot R, Montagne B, Mazel D, Ricchetti M: An end-joining repair mechanism in Escherichia coli. Proc Natl Acad Sci USA 2010, 107(5):2141-2146.

58. Diederich $L$, Roth $A$, Messer W: A versatile plasmid vector system for the regulated expression of genes in Escherichia coli. Biotechniques 1994, 16(5):916-923.

59. Miller JH: Experiments in Molecular Genetics Cold Spring Harbor, NY: Cold Spring Harbor Laboratory Press; 1972.

60. Wong ML, Medrano JF: Real-time PCR for mRNA quantitation. Biotechniques 2005, 39(1):75-85.

61. Zuker M: Mfold web server for nucleic acid folding and hybridization prediction. Nucleic Acids Res 2003, 31(13):3406-3415.

62. Heus HA, Pardi A: Structural features that give rise to the unusual stability of RNA hairpins containing GNRA loops. Science 1991, 253(5016):191-194

doi:10.1186/1471-2199-11-87

Cite this article as: Kaw and Blumenthal: Translational independence between overlapping genes for a restriction endonuclease and its transcriptional regulator. BMC Molecular Biology 2010 11:87.

\section{Submit your next manuscript to BioMed Central and take full advantage of:}

- Convenient online submission

- Thorough peer review

- No space constraints or color figure charges

- Immediate publication on acceptance

- Inclusion in PubMed, CAS, Scopus and Google Scholar

- Research which is freely available for redistribution

Submit your manuscript at www.biomedcentral.com/submit
Biomed Central 